\title{
Entrevista com Manoel Tosta Berlinck
}

(Concedida a Mario Eduardo Costa Pereira, em São Paulo, em agosto de 2000)

Manoel Berlinck, o Sr., que foi o introdutor da Psicopatologia Fundamental no Brasil poderia nos contar como isso se deu e, exatamente, ao que se propõe?

Na verdade há um certo exagero em se dizer que fui o introdutor da Psicopatologia Fundamental no Brasil. Ela foi trazida por Pierre Fédida, que nos visita para realizar uma série de trabalhos a cada dois, três anos, durante os últimos trinta anos. Foi ele quem cunhou essa expressão "Psicopatologia Fundamental” na Universidade de Paris 7 Denis Diderot. Sou responsável pela criação do Laboratório de Psicopatologia Fundamental do Programa de Estudos Pós-Graduados em Psicologia Clínica da Pontifícia Universidade Católica de São Paulo - um grupo permanente de pesquisa nessa área do saber científico. Sou, também, responsável por alguns desdobramentos dessa iniciativa. Assim, criei, graças a uma associação com Mário Pereira, a Revista Latinoamericana de Psicopatologia Fundamental, em março de 1998 e, depois disso, iniciei a Rede Universitária de Pesquisa em Psicopatologia Fundamental que reúne, hoje, aproximadamente 34 pesquisadores de 23 Universidades brasileiras, 1 pesquisador da Argentina, 1 pesquisador do Uruguai, 1 pesquisador do México e 2 pesquisadores de duas Universidades francesas. Produzi, em seguida, a Biblioteca de Psicopatologia Fundamental, uma série de livros publicados pela Editora 
Escuta. Neste meio tempo, Mário Pereira havia iniciado o Laboratório de Psicopatologia Fundamental do Departamento de Psicologia Médica e Psiquiatria da Faculdade de Ciências Médicas da Universidade Estadual de Campinas - Unicamp, Ney Branco de Miranda organizou o Laboratório de Psicopatologia Fundamental da Faculdade de Psicologia da Universidade Mackenzie, Edilene Freire de Queiroz deu início ao Laboratório de Psicopatologia Fundamental e Psicanálise do Departamento de Psicologia da Universidade Católica de Pernambuco - Unicap e Mériti de Souza, o Laboratório de Psicopatologia Fundamental da Faculdade de Filosofia e Ciências Humanas da Universidade Estadual Paulista - Unesp-Assis.

E, então, afinal de contas, do que se trata quando se trata da Psicopatologia Fundamental?

Trata-se, antes de mais nada, de uma concepção específica da doença mental, ou seja, a Psicopatologia Fundamental concebe a doença mental como um excesso, como alguma coisa referida àquilo que se chama "o pathos", e tem uma longa tradição psiquiátrica. Mas que não supõe nenhuma lesão cerebral determinante; supõe, isso sim, a existência de uma subjetividade. Em outras palavras, a Psicopatologia Fundamental trabalha com o pressuposto de que a única espécie animal que possui um sofrimento intrínseco é a espécie humana, e que esse sofrimento decorre de excesso. Esse excesso é de natureza psíquica, vale dizer, não é algo exclusivamente físico, ainda que o psiquismo seja parte do biológico.

A Psicopatologia Fundamental é assim denominada para se distinguir, em primeiro lugar, da Psicopatologia Geral, ou seja de uma Psicopatologia que pretende fazer um discurso a respeito das doenças existentes e como é que elas se caracterizam, a Psicopatologia Fundamental pretende trabalhar com a constituição de uma experiência, ou seja, a partir do vivido na clínica psicoterapêutica.

Em terceiro lugar, a Psicopatologia Fundamental parte do pressuposto de que nenhum discurso organizado existente na atualidade esgota o conhecimento a respeito do sofrimento psíquico e que, portanto, é necessário um campo no qual a interlocução entre ocupantes de diferentes posições - psiquiatras, psicólogos, psicanalistas, filósofos, cientistas sociais, jornalistas, artistas - realizem interlocuções sem ter de abrir mão das posições que ocupam e que essas interlocuções ajudem cada um a especificar, cada vez melhor, sua própria posição. Isso só é possível se os que participam dessas interlocuções se debruçarem sobre um determinado problema referente ao pathos. Aí é possível se esquecer momentaneamente das ortodoxias e buscar uma compreensão mais acurada do problema, uma resposta mais satisfatória para ele.

A Psicopatologia Fundamental não contém, portanto, um projeto interdisciplinar, mas pretende desenvolver um projeto de interlocuções multidisciplinares em que as 


\section{EN TREVISTAS}

posições são resguardadas, em que cada um dos interlocutores possa elaborar seu próprio discurso, que vai construindo paulatinamente, sofredoramente. É esse discurso construído num campo de interlocução, que parte do vivido na clínica psicoterapêutica e que reconhece a natureza inesgotável desse mesmo vivido, que pode ser chamado de Psicopatologia Fundamental.

Mas, então, o Sr. diria que a Psicopatologia Fundamental tem por especificidade estudar o sofrimento como tal?

O sofrimento humano psíquico como tal, ou seja, o sofrimento entendido como um excesso, como aquilo que incomoda, como o que perturba e que provoca uma insatisfação, um transtorno, é uma questão muito mais ampla do que aquilo que se denomina doença mental, hoje em dia. Doença mental é uma coisa que a pessoa diz: "eu estou doente" - isso está incluído na Psicopatologia Fundamental -, mas há coisas que as pessoas dizem: "não, não estou doente, mas estou incomodado; estou perturbado por alguma coisa que me incomoda, que está dentro de mim e que quero entender o que é”. São esses tipos de coisas que interessam à Psicopatologia Fundamental. Se a Psicopatologia Experimental tiver algo a dizer sobre esse assunto, então ela é muito bem-vinda a esse campo de interlocuções. Mas se ela tiver o que dizer somente sobre ratos ou macacos e seus comportamentos, então seria uma perda de tempo tentar conversar com os que estão empenhados em compreender o pathos psíquico.

Mas o Sr. diria, então, que a Psicopatologia Fundamental é uma nova disciplina, ou se trata de um campo de interlocução entre diversas disciplinas?

Ela não é uma nova disciplina. Definitivamente minha visão não é essa. Vejo a Psicopatologia Fundamental como um campo de pesquisas e de interlocuções entre posições diferentes, empenhadas em compreenderem o pathos psíquico a partir do vivido na atividade clínica. Clinicar, aqui, recupera essa dimensão tradicional da palavra em que o inclinar-se sobre alguém ou alguma coisa de alguém é uma posição favorável à compreensão. Nessa atividade do inclinar-se para melhor compreender, do clinicar, não se trata de defender um ponto de vista teórico-metodológico qualquer, mas de permitir que diferentes pontos de vista sejam formulados a partir do inclinar-se sobre o sofrimento psíquico. Acredito que só assim vamos poder nos enriquecer, ou seja, só assim poderemos produzir - porque se trata de uma verdadeira produção - discursos mais complexos, precisos e claros que representem condignamente nossa vivência clínica. É isso, esse trabalho produtivo de palavras representativas do vivido na clínica que chamo de experiência a respeito do sofrimento psíquico. Se disciplina há na Psicopatologia Fundamental é esse trabalho produtivo de encontrar palavras claras e precisas representando o mais condignamente possível o vivido na intimidade da clínica, com o que está sofrendo. 
De qualquer maneira, estudar o campo da Psicopatologia pelo vértice do sofrimento implica uma posição ética.

Ah, sim, no seguinte sentido: estabelece uma especificidade para a noção de sofrimento que não é meramente considerado um prejuízo, uma deficiência que necessita ser eliminada visando a restauração de um status quo ante, um estado anteriormente existente (mesmo que seja no imaginário do psicoterapeuta). Não estamos tratando só de doentes mentais, de pessoas prejudicadas socialmente porque sofrem de uma doença mental, estamos interessados nelas, evidentemente, mas também estamos interessados numa posição ética no sentido de nos interessarmos em compreender a natureza subjetiva do sofrimento psíquico, o que está se passando com o que sofre, pois só assim será possível constituir uma experiência psicoterapêutica, ou seja, um discurso (logos) sobre o sofrimento (pathos) psíquico, sendo, ao mesmo tempo, um tratamento. Vale dizer, uma psico-pato-logia. Nesse sentido, a descrição regulamentada de transtornos mentais determinando procedimentos psicofarmacológicos é insuficiente para constituir uma psicopatologia. A medicina não pode ser reduzida a uma atividade receitadora de remédios a partir de descrições regulamentadas de transtornos mentais, a não ser que se queira abrir mão da longa e rica tradição médica de escutar o doente para melhor compreender seu sofrimento e de colocar em palavras o vivido na clínica para que outros possam disso se beneficiar. A receita de remédios a partir de uma descrição regulamentada da doença sempre foi uma atividade farmacêutica e se os médicos se conformarem com esta vantajosa proposta para a indústria farmacêutica deixarão de ser médicos e passarão a ser agentes farmacêuticos transformando-se em empregados de eficientes supermercados de remédios. A medicina sempre se empenhou na busca de palavras para a narrativa psicopática de cada paciente, palavras esclarecedoras servindo para tratar esse mesmo paciente (agente em sofrimento).

E qual a relação entre a Psicopatologia Fundamental e a Psicanálise?

Essa questão pode ser colocada mais amplamente. Coloco a questão, hoje, da seguinte forma: qual é a relação da Psicopatologia Fundamental com a subjetividade? Porque estou convencido de que o grande debate contemporâneo gira em torno de se a espécie humana é subjetiva ou não é subjetiva, ou seja, se as manifestações da espécie humana se devem a fatores que se pode objetificar, que se pode reduzir a um âmbito exclusivamente objetivo, passível de um conhecimento empírico hipotético-dedutivo. Se considerarmos a subjetividade humana, tal como ela é hoje concebida, como manifestação em que se pode encontrar razões objetivas para ela, então poderemos controlar e regulamentar essa subjetividade, ou seja, ela deixará de ser subjetividade. 


\section{EN TREVISTAS}

É preciso que fique claro que não sou um adepto da subjetividade. Ao contrário, considero a subjetividade um verdadeiro estorvo. Trata-se de uma enorme perturbação para o humano, pois não se dobra à cultura, à civilização. Como sou um adepto da civilização, prefiriria que a humanidade não fora subjetiva. Mas... lamento, lamento por mim, mas a humanidade é subjetiva, ou seja, há manifestações excessivas no humano que não são redutíveis à civilização. Não devemos, entretanto, nos conformar com essa situação incômoda. É preciso trabalhar incansavelmente para, como diz Freud, fazer com que ali, onde o id era, o ego advenha.

O Sr. quer dizer, então, que as pessoas se constituem uma a uma?

Creio ser necessário relembrar sempre, com freqüência, que o humano é uma espécie composta de singularidades. Além disso, o humano é uma espécie animal. Uma espécie animal produtora de civilização. Não reconheço nenhuma transcendência no humano. A subjetividade é aquilo que em cada membro da espécie o torna singular e não se reduz à civilização. A subjetividade possui um estatuto de real. Ela resiste a qualquer representação e, por isso, é irredutível à civilização. O humano é, então, não só um animal que produz civilização. Ele é, principalmente, um animal singular, subjetivo, que enfrenta essa singularidade subjetiva produzindo civilização. A psicopatologia é o discurso que representa esse paradoxo: o de sermos, ao mesmo tempo, membros de uma espécie animal e singularidades subjetivas. É por isso que sofremos a tentação de aniquilar a singularidade em favor de uma civilização, pois esta suporta muito mal a subjetividade, a singularidade humana. O projeto da Psicopatologia Fundamental é, pois, evidentemente pretensioso e inalcançável: construir um discurso (uma civilização) representativo desse paradoxo vivido na clínica psicoterapêutica para melhor tratar o pathos psíquico.

Mas o Sr. não teme que, em tomando o sofrimento como ponto de discussão, a Psicopatologia Fundamental acabe, justamente, por objetivar o pathos?

O ideal almejado pela Psicopatologia Fundamental não deve ser o de objetivar o pathos na medida em que reconhece a natureza singular e subjetiva dos membros da espécie humana. O que se pretende com a Psicopatologia Fundamental é algo muito exigente e complexo: colaborar, de forma muito precisa, com essa grande tarefa humana: permitir que o ego advenha ali onde o isso era tratando, ao mesmo tempo, do pathos.

A Psicopatologia sempre se caracterizou por ser uma encruzilhada onde convivem disciplinas das orientações mais diversas, e o termo Torre de Babel é freqüentemente usado para descrever esse encontro. Em que base pensa o Sr., então, que é possível reunir pessoas vindas de horizontes teóricos e metodológicos tão diferentes, sob a Psicopatologia Fundamental, quais são as bases para tal diálogo? 
As bases são as que denomino de ambientais, ou seja, quais são as condições que podem proporcionar uma interlocução entre diferentes, a respeito de um objeto comum?

Minha posição é a de que a universidade pode oferecer um ambiente, um meio favorável para esse tipo de interlocução, pois se trata de uma instituição que tem uma tradição secular de diálogo multidisciplinar. "A universidade”, como dizia o Prof. Zeferino Vaz, fundador e primeiro reitor da Universidade Estadual de Campinas, "é uma unidade na diversidade”, e essa unidade na diversidade é que proporciona a possibilidade de interlocução entre diferentes, em que as posições podem ser respeitadas; não há nenhum interesse em converter o outro à sua própria posição, ainda que haja uma forte tentação retórica nesse tipo de interlocução.

Porém, o Sr. diz que é a partir do vivido na clínica que se desenvolve a pesquisa em Psicopatologia Fundamental. Por que, então, a Universidade seria um bom ambiente para esse tipo de pesquisa?

Há, na atualidade, vários meios em que a pesquisa em Psicopatologia Fundamental pode se desenvolver. Alguns são mais favoráveis, outros são inadequados. As instituições de formação de psicanalistas e as universidades são bons ambientes para a pesquisa. Hospitais, ambulatórios, clínicas podem ser bons ambientes psicoterapêuticos, mas, em geral, não estão voltados para a pesquisa. Desconheço o funcionamento interno das instituições de formação. Mas, assim mesmo, é óbvio que devem estar preocupadas com a transmissão de uma determinada ortodoxia e isso é indispensável para a formação. Um psicanalista precisa estudar a fundo pelo menos Freud e mais um psicanalista que constitui ianos, seja Klein, Lacan, Winnicott ou Bion. Esse estudo deve ocorrer concomitantemente à sua análise pessoal e à análise de controle ou supervisão. Essas atividades são intensas e demoradas. Suponho, por outro lado, que seja nesse período de formação em que o psicanalista começa a formular um projeto de pesquisa. Mas, as instituições de formação, como o próprio nome indica, estão voltadas para a transmissão da psicanálise incluindo, aí, um espírito de pesquisa que só poderá se desenvolver quando o psicanalista estiver avançado na sua formação. Além disso, a pesquisa requer um afastamento da preocupação com a ortodoxia e uma concentração da atenção com um problema de investigação. Em outras palavras, o psicoterapeuta deve parar de repetir o que Freud, Lacan, Klein, Winnicott, Bion etc., disseram e passar a buscar uma construção metapsicológica específica para seu problema de investigação, para o mal-estar vivido na clínica. Trata-se, aqui, de encontrar palavras para o vivido em sua clínica. Palavras próprias e não repetições adequadas, pois nenhum texto esgota o vivido na clínica. A universidade, neste caso, possui uma tradição de liberdade de pensamento e de pesquisa desenvolvida nos últimos novecentos anos. Falo, aqui, da universidade voltada para o ensino e a pesquisa e 


\section{EN TREVISTAS}

não estou me referindo às escolas de terceiro grau, voltadas exclusivamente para o ensino.

Para concluir, o tema do Congresso Brasileiro de Psicopatologia Fundamental é: nesse momento de mudança de milênio, quais os novos desafios e os novos limites de uma reflexão sobre o sofrimento psíquico. No seu ponto de vista, quais são os grandes desafios para a Psicopatologia nesse século que começa?

Em primeiro lugar, o grande desafio está na possibilidade de a gente sustentar esse debate entre o objetivo e o subjetivo. Se não formos capazes de sustentar esse debate estaremos incorrendo num grave erro, pois abriremos mão da imperiosa tarefa de melhor compreensão do fenômeno humano.

Em segundo lugar, questão que precisa ser levada em consideração é a questão epidemiológica, ou seja, se há ou não e como é que se manifesta, e como é que se organiza essa questão do sofrimento desde o ponto de vista da epidemia; se o sofrimento pode ser coletivo - o sofrimento psíquico, bem entendido - ou não. Parece que sim, e isso é muito interessante, porque temos de pensar no que acontece coletivamente, quais são as condições ambientais e sociais que produzem, por exemplo, uma loucura tipo Canudos, ou tipo Holocausto, ou tipo Processo argentino e como é que a sociedade se relaciona com essas situações, especialmente uma sociedade democrática como almejamos para o Brasil.

A terceira questão é propriamente a psicoterapêutica, ou seja, quais os ambientes mais adequados para o tratamento da doença mental e do sofrimento humano? É necessário avançar nesta questão porque estão ocorrendo numerosas modificações ambientais e elas precisam ser levadas em conta. Assim, por exemplo, o consultório particular, há muito tempo, já não é o único ambiente em que se pratica a psicoterapia. Hospitais gerais e manicômios, hospitais-dia, clínicas psiquiátricas, ambulatórios e até a imprensa têm acolhido a prática psicoterapêutica. Não basta a gente liquidar os hospícios. Essas mudanças são relativamente recentes e é necessário pesquisar como se encaminha a questão do bom trato, em que meios se trata bem do sujeito. Esse é um problema que começou a ser debatido nos anos 1960 e precisa continuar sendo pesquisado e debatido.

A última questão, mas não menos importante, é a da ortodoxia versus a heterodoxia, ou seja, se formos defender nossas posições em nome de interesses político-ideológicos e não de interesses científicos, nos enfraqueceremos muito. Não sou a favor de ficar sustentando qualquer posição que seja em nome de interesses político-ideológicos. Sou a favor da pesquisa científica e da interlocução nascida dessa atividade, pois é assim que poderemos perceber nossos próprios preconceitos e nossas ideologias, nossas estereotipias, nosso discurso estereotipado e massificado e o que fazer com ele. 